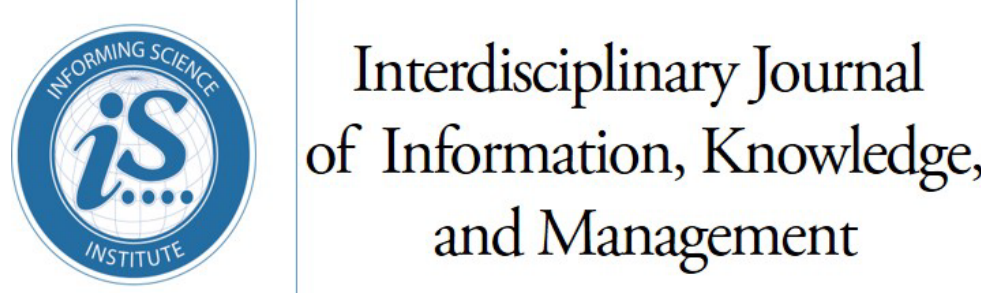

An Official Publication

of the Informing Science Institute

InformingScience.org

IJIKM.org

Volume 12, 2017

\title{
ICT-PlatForm TO TRANSFORM CAR DEALERSHIPS TO REgional Providers of SuSTAINABle Mobility SERVICES
}

$\begin{array}{lll}\text { Benjamin Wagner vom Berg* * } & \text { Carl von Ossietzky University of } & \text { benjamin.wagnervomberg@uni- } \\ & \text { Oldenburg, Oldenburg, Lower } & \text { oldenburg.de } \\ & \text { Saxony, Germany } & \\ \text { Jorge Marx Gómez } & \text { Carl von Ossietzky University of } & \text { jorge.marx.gomez@,uni- } \\ & \text { Oldenburg, Oldenburg, Lower } & \underline{\text { oldenburg.de }} \\ & \text { Saxony, Germany } & \\ \text { Alexander Sandau } & \text { Carl von Ossietzky University of } & \text { alexander.sandau@,uni- } \\ & \text { Oldenburg, Oldenburg, Lower } & \text { oldenburg.de }\end{array}$

\section{ABSTRACT}

Aim/Purpose

The topic of this study is the ICT-enabled transformation of car dealerships to regional providers of sustainable mobility (e.g., car sharing).

Background Car dealerships offer specific conditions that enable a sustainable mobility offer, based on individual motorized transport like car sharing. This is especially useful in small towns or rural areas where people's mobility is strongly dominated by private cars, and public transport coverage is limited. However, these new mobility services are combined services with the need of a deep integration of information systems, and these services are not yet related to car dealerships and customer acquisition has to be supported.

Methodology An empirical study with an inductive approach was chosen. The study consists of interviews with three focus groups of different stakeholders of car dealerships. Within the frame of the research project, "ReCaB - Regional CarBalancing" a qualitative research approach was chosen. Within a design science approach the existing SusCRM architecture was adapted based on the elaborated requirements.

Contribution A software architecture is proposed, where Customer Relationship Management (CRM) components to market new sustainable mobility offers are vital parts and existing information systems of car dealerships are integrated.

Findings

The basic feasibility of the establishment and customer acceptance has been demonstrated, at least in the area of car sharing within ReCaB. The execution in

Accepted by Editor Ewa Ziemba |Received: June 3, 2016| Revised: November 7, 2016; December 10, 2016; January 8, 2017; January 25, 2017 Accepted: January 26, 2017.

Cite as: Wagner vom Berg, B., Marx Gómez, J., \& Sandau, A. (2017). ICT-platform to transform car dealerships to regional providers of sustainable mobility services. Interdisciplinary Journal of Information, Knowledge, and Management, 12, 37-51. Retrieved from http://www.informingscience.org/Publications/3652

(CC BY-NC 4.0) This article is licensed it to you under a Creative Commons Attribution-NonCommercial 4.0 International License. When you copy and redistribute this paper in full or in part, you need to provide proper attribution to it to ensure that others can later locate this work (and to ensure that others do not accuse you of plagiarism). You may (and we encourage you to) adapt, remix, transform, and build upon the material for any non-commercial purposes. This license does not permit you to use this material for commercial purposes. 
the car sharing field has already started and a number of car dealerships are already bringing their own offers to market. Major findings for the SusCRM architecture have been elaborated in a design science approach in the national German research project "Showcase for electro mobility".

Recommendations There is still no fully functional prototype developed for this specific use case for Practitioners and evaluated in the car dealership environment. An implementation only, based on own efforts, is difficult for car dealerships because of the dealership's lack of know-how as well as tight IT budgets. However, this approach appears particularly successful in rural areas where public transport services are heavily declining. For full implementation, the presented ICT support is imperative.

Recommendation The research on the retailer level, especially in combination with a digital transfor Researchers formation by the use of ICT systems, is still fragmentary. Research in this area that both addresses sustainability goals on a general level and supports economical goals on the company level of automotive retailers would be useful.

Impact on Society Creation of sustainable offers as a substitute or supplement for mobility based on their own car is a promising way to reduce negative effects of mobility. Enhancement of the mobility of the people in rural areas is leading to a more active lifestyle by reaching the leisure facilities, workplaces and educational institutions in a sustainable manner.

Future Research In terms of the fast changing mobility landscape, especially on a technical level with the development of autonomous vehicles and digitalization of entire businesses new solutions are becoming accessible, that have to be integrated in further research.

Keywords car dealership, automotive retailer, car sharing, SusCRM, sustainability CRM, sustainable mobility, rural regions

\section{INTRODUCTION}

Companies, politics and the public nowadays realize that resources are limited and various problems in the economic, social and environmental dimension are resulting from our economic activities as well as consumer behavior (Belz \& Peattie, 2009).

In the context of energy consumption and $\mathrm{CO}_{2}$ emissions, the transportation sector plays a central role and is one of the most relevant fields of sustainable consumption (Deutscher Bundestag, 1998). $26 \%$ of global $\mathrm{CO}_{2}$ emissions are produced by the combustion of fossil fuels in transport. $35 \%$ of the total energy demand in the EU is consumed by transportation, $71 \%$ by road transport (EEA, 2011). Considering the transport mix (modal split) we recognize that a large amount of our mobility is still carried out by light duty vehicles (LDV). While LDV cause the most negative effects in terms of emission, 83\% of the mobility in Europe 28 in 2012 was carried out by LDV (Eurostat, 2015), coincidently $60 \%$ of $\mathrm{CO}_{2}$ emissions were caused by LDV (EEA, 2013). Until 2050 a worldwide increase of $\mathrm{CO}_{2}$ emissions by $50 \%$ caused by LDV is expected, resulting in an urgent national and international need for action (International Transport Forum, 2010).

In the case of the mobility of people, the creation of sustainable offers as a substitute or supplement for mobility based on their own car is a promising way to reduce negative effects of mobility in a significant way (Black, 2010). In this context, besides other innovations in products and production processes, the ecologically, sustainably and economically efficient design of services plays a central role (Mont, 2002). Assuming an increasing consumption of individuals, with contemporary doubling of the world population, the resource consumption of industrial companies needs to be decreased by $90 \%$ in the next 50 years (Ceschin, 2010). This forecast inevitably leads to a rethinking of possessionoriented consumer practices. The so-called product service systems (PSS) are based on the concept of functional use, which implies the satisfaction of needs through the use of products and not 
through possession (Hinterberger, Burger, Jasch, Kaltenegger, \& Hammerl, 2008). One of the best known examples of PSS systems is car sharing. Car sharing increases the sustainability of mobility due to several advantages:

- In general, cars used for car sharing services are small, new and eco-efficient.

- Car sharing is very suitable to be combined with electric mobility (Firnkorn \& Müller, 2015).

- Car sharing can motivate intermodal travelling in combination with public transport.

The car sharing market is growing worldwide (e.g. in South Africa Locomute is successfully operating in different cities). The automotive industry, especially manufacturers, entered this market many years ago. Two major German automobile manufacturers - not least due to the changed consumer habits already successfully operate in the market with their own car sharing services (car2go/Daimler, Drive Now/BMW) (Lenz \& Fraedrich, 2016). These new offers are strongly connected to a general process of digital transformation of the automobile manufacturers (Hanelt, Piccinini, Gregory, Hildebrandt, $\&$ Kolbe, 2015). However, this transformation process does not apply to automotive retailers. At the same time, they are in a serious economic struggle because of decreasing sales volumes and margins (Albuquerque \& Bronnenberg, 2011).

A transformation to a mobility service provider (MSP) possibly offers opportunities for car dealerships to ensure the long-term existence and simultaneously contribute to a more sustainable mobility (Bellini, Dell'Era, Frattini, \& Verganti, 2016; Canzler \& Knie, 2009). New offers can be set up for car sharing but also e.g. for innovative fleet management. At the same time, a combination of these new services with the existing service portfolio holds an interesting synergy potential for the retailers (Mehl \& Kuhnert, 2013). In order to successfully transform car dealerships to MSPs, the adjustment of the business model and the integration of new and existing processes is necessary. As a key prerequisite for the synchronization of existing and new processes and for the implementation of new customer processes an innovative Information and Communication Technology (ICT) architecture is mandatory (Mehl \& Kuhnert, 2013).

In this article, the results of the EFRE-funded (European Funds for regional development) capability and feasibility study "ReCaB - Regional Car-Balancing" of 2014 are presented. Using an inductive research approach with qualitative research methods based on focus groups, Carl von Ossietzky University investigated how a transformation of car dealerships to regional mobility providers can be achieved. A group of car dealerships from Oldenburg, Germany served as the empirical object of investigation. The subject of research was the use of existing resources within a new business model and new services like car sharing, along with the integration of the old business model and the identification of potential synergies. The focus lies on the demand side as well as the economic and technical feasibility. As a preliminary research base the Sustainability Customer Relationship Management (SusCRM) conception (Wagner vom Berg, 2013, 2015) with its prototypical implementation in the German national research project "Showcase for electro mobility" was used.

The remainder of this paper is structured as follows. Based on a literature review, the SusCRM conception and studies of the mentioned projects a concept of new mobility services for automotive retailers on market and process levels is presented. These are considered as preliminary works to come up with a software architecture for digital transformation of car dealerships.

\section{LITERATURE REVIEW}

The literature review is mainly based on the following databases: Google Scholar, CSDL, MS Academic Search and Research Gate.

\section{DIGITAL TRANSFORMATION IN THE AUTOMOTIVE SECTOR}

An investigation of literature in the fields of digital transformation of automotive manufactures, digital transformation of car retailers and car dealership based on car sharing services has been con- 
ducted. The resulting bulk of literature was located in the field of business models and innovation management.

Many automotive manufacturers face the challenges accompanied by the digitalization of the industry. Besides, topics of Industry 4.0 with the term of "smart factory", the manufactures are trying to fulfill a digital transformation of their primarily physical business with a balance between the core competences and new digital trends. These changes lead to enabled rapid pace of product and service innovations, shorter product life cycles, and cross-boundary industry disruptions (Setia, Venkatesh, \& Joglekar, 2013). A lot of work is carried out in the fields of social media, mobile applications, big data and cloud computing in order to extend, revise, terminate, and create business models (Hanelt et al., 2015). However, the digital transformation of industrial-age products has remained surprisingly unnoticed in IS literature (Yoo, Henfridsson, \& Lyytinen, 2010). Especially, the combination of vehicle-based ICT and consumer-based ICT are essential elements to succeed (Berman \& Bell, 2011). Applied management and IS research is still underexplored and elaborated digital transformation impacts are not provided (Fitzgerald, Kruschwitz, Bonnet, \& Welch, 2014). In relation to mobility, consumers' new digital lifestyles expect new digital businesses and services like car sharing (Rishi, Stanley, \& Gyimesi, 2012; Desyllas \& Sako, 2013). At the same time, new (digitally based) services are suitable to reduce the overall mobility quantity in a significant way (Shaheen, Camel, \& Lee, 2012).

The research field of car sharing, especially free-floating car sharing, is mostly investigated in German field studies on car2go fleets (Schmöller, Weikl, Müller, \& Bogenberger, 2015) and on a few international test fields (Wielinski, Trépanier, \& Morency, 2015; Terriena, Maniak, Chenb, \& Shaheen, 2016; Ciari, Balac, \& Balmer, 2015). This research field is enhanced by focusing on electric vehicles in free-floating car sharing (Firnkorn \& Müller, 2015). Nevertheless, research in the field of digitalization of automotive retailers/dealers, especially as providers of car sharing services, is neglected (cf. Bellos, Ferguson, \& Toktay , 2016; Athanasopoulou, Bowman, Nikayin, \& de Reuver, 2016). Albuquerque and Bart are investigating the effects of demand shocks on car dealer networks, especially on profits, prices and the network itself (Albuquerque \& Bronnenberg, 2011). Bellini et al. (2016) focus on innovation in the automotive retail industry. They performed empirical research on new strategic innovation projects for car dealers.

A combination of new services, such as promoting car sharing or carpooling with the existing service portfolio, holds an interesting synergy potential for retailers (Mehl \& Kuhnert, 2013). At the same time, the establishment of car dealerships as mobility providers appears to be a promising approach to solve mobility problems in rural areas and smaller cities. The example of the manufacturer shows that car sharing offers are first established successfully in large cities. The reasons are the profitableness (particularly in the central areas) and the larger customer potential especially for a flexible floating car sharing concept (Wilke, Böhler, Bongardt, \& Schäfer-Sparenberg, 2007). While in big cities car sharing offers are more represented as a competition to highly developed public transportation, car sharing offers in the rural area are able to promote the use of public transport (Stutzbach, Raabe, Pfriem, \& Becker 2001).

In connection with electric and multimodal mobility, the combined use of several means of transport plays an important role. Thus, technically related disadvantages of electric vehicles (EV) in terms of range and flexibility are compensated by the combined use of, for example, railway services. In general, multimodal mobility allows compensating disadvantages according to sustainability compared to solely car based mobility by combining different modal modes, such as walking, cycling, public transport and car sharing. From the perspective of the traveler, the mean of transport is chosen, which is most satisfying for the specific situation and individual needs (Steg \& Vlek, 2009).

Based on these insights and further empirical studies, a concept for a new mobility offer from automotive retailers is designed as follows. 


\section{SUSCRM AND EMIS IN TRANSPORTATION DOMAIN}

The SusCRM conception is the major preliminary work for this article. An extensive literature review for the conception was presented in Wagner vom Berg (2015) and is not repeated here. However, the conception and its contribution to EMIS are important and introduced shortly.

The role of information and communication technologies (ICT) in the context of sustainable development is discussed frequently. So far, most studies in EMIS (Environmental Management Information Systems) are dedicated to issues such as resource and energy efficiency during production processes (Hilty, 2010; Hilty, Lohmann, \& Huang, 2011), leading to the development of corporate environmental management information systems (Rautenstrauch, 1999). However, these efficiency gains may be lost by using the corresponding good or service to a greater extent, leading to rebound effects (Hilty, 2010; Hilty et al., 2011). Thus, for enabling sustainability by ICT, deep structural changes are necessary, including radical changes in consumption patterns.

The integration of ICT into sustainable mobility services plays a central role; for example, for the planning of intermodal trip chains or to find car sharing vehicles (Car2go). The implementation and adaptation of information systems is required both on the supplier and on the customer side. On the one hand, they enable the proposed sustainable mobility offers; on the other hand, to make offers more attractive and to actively market them on grounds of sustainability. The presented solution leans to the general design and in particular the ICT architecture on the study "Conception of a Sustainability Customer Relationship Management (SusCRM) for providers of sustainable mobility" (Wagner vom Berg, 2015). The work provides an information technology concept for the development of a SusCRM for providers of sustainable mobility services with different design levels, including an architectural proposal. The main objective is to change the mobility behavior of customers with regard to sustainability, taking into account the supplier goals of customer acquisition and customer retention. The concept aims at all providers of sustainable mobility, e.g. public transport providers, but also at providers of new mobility services like car sharing and carpooling or integrated multimodal mobility services. The main requirements of a SusCRM for mobility providers, e.g. the information and technical support of customers in the intermodal trip planning, are implemented here in the case of the car dealership. The developed system can be classified as a "system of marketintegrated environmental protection" of the EMIS (see Figure 1).

\begin{tabular}{|c|c|c|c|c|c|c|c|c|}
\hline \multicolumn{9}{|c|}{ Environmental Management Information Systems (EMIS) } \\
\hline \multicolumn{2}{|c|}{$\begin{array}{l}\text { Information- } \\
\text { and Reporting- } \\
\text { Systems }\end{array}$} & \multicolumn{2}{|c|}{$\begin{array}{l}\text { Eco-Controlling- } \\
\text { Systems }\end{array}$} & \multicolumn{2}{|c|}{$\begin{array}{c}\text { Systems of } \\
\text { Market-integrated } \\
\text { Environment Protection }\end{array}$} & \multicolumn{3}{|c|}{$\begin{array}{c}\text { Systems of } \\
\text { Production-integrated } \\
\text { Environment Protection }\end{array}$} \\
\hline $\begin{array}{l}\text { Gov- } \\
\text { ern- } \\
\text { ment }\end{array}$ & Society & $\begin{array}{c}\text { KPI- } \\
\text { Systems }\end{array}$ & $\begin{array}{l}\text { Eco- } \\
\text { Balance- } \\
\text { Systems }\end{array}$ & $\begin{array}{l}\text { Marketing- } \\
\text { oriented } \\
\text { Systems }\end{array}$ & $\begin{array}{l}\text { Consumption- } \\
\text { oriented } \\
\text { Systems }\end{array}$ & $\begin{array}{l}\text { Input- } \\
\text { oriented } \\
\text { Systems }\end{array}$ & $\begin{array}{l}\text { Process- } \\
\text { oriented } \\
\text { Systems }\end{array}$ & $\begin{array}{l}\text { Output- } \\
\text { oriented } \\
\text { Systems }\end{array}$ \\
\hline \multicolumn{5}{|c|}{ Corporate Sustainability Reporting } & \multicolumn{4}{|c|}{ Environmental Information Management } \\
\hline
\end{tabular}

Figure 1. Expansion of EMIS (Wagner vom Berg et al. 2016)

The market-integrated environmental protection system is a vital complement to the EMIS, because in a market-oriented economy, the demand for goods is decisive for the type and quantity of production. This perspective ultimately applies to an earlier stage than the "production-integrated environmental protection". Customers are directly involved within "consumption-oriented systems", by providing environmental and sustainability-related information for their personal consumption as a decision basis. "Marketing-oriented systems" are supporting sales and marketing of sustainable products as well as services based on sustainability information and by improving accessibility and provision. In these terms, the proposed system is considered as a "System of Market-integrated Environment Protection" by adopting the SusCRM approach. 


\section{METHODOLOGY}

For the preliminary work of the "Conception of a Sustainability Customer Relationship Management (SusCRM) for providers of sustainable mobility services" (Wagner vom Berg, 2015), a design science approach has been chosen. The design science method was mainly developed by Hevner and focuses on the development of innovative artefacts with assuring relevance and rigor of these (Hevner \& Cahterjee, 2010; Hevner, March, Park, \& Ram, 2004). As a main contribution, the SusCRM approach provides a software architecture that was adopted and adapted in this work. For the development of the SusCRM, methods and reference models of business engineering and business information systems science have been integrated (Neckel \& Knobloch, 2007; Österle \& Blessing, 2000; Rautenstrauch, 2001; Speshock, 2010). A prototype was developed, implemented and evaluated within the national German project "Showcase for electro mobility".

In the research project "ReCAB", the focus was to design a concept how new sustainable mobility services from automotive retailers can be successfully brought to market. For this, three perspectives have been investigated within an empirical study:

- Business models and market perspective.

- Process perspective.

- Technological perspective.

The subject of investigation within an inductive approach was the automotive retailer "Braasch group" with four main sites and 180 employees. As a first step, existing offers, processes and information systems at the Braasch group have been analyzed. As a main tool of the empirical study, focus groups have been built and interviews were conducted. "A focus group is a special type of group in terms of purpose, size, composition, and procedures" (Krueger \& Casey, 2000). Focus groups are traditionally used in social science research (Merriam, 2009) to gain new insights regarding attitudes, experiences, perspectives and objectives of a focused topic by discussing them within a related group of people (Krueger \& Casey, 2000; Richards \& Morse, 2013; Subramony, Lindsay, Middlebrook, \& Fosse, 2002). Focus groups combine interview and observational techniques (Teddie \& Tashakkori, 2008) to gain knowledge in a (particularly unknown) topic (Richards \& Morse, 2013). The use of social science methods is suitable in this research approach because traditionally (in Germany) social scientists are the main contributors to research in mobility topics (Canzler \& Knie, 1994; Knie, 2005).

In $\mathrm{ReCaB}$, three focus groups have been built with 5-9 members each. Two focus groups (one with private customers and one with business customers of Braasch) were mainly utilized to explore the requirements for the new mobility services from a market perspective. The third focus group contained experts from automotive industry and was used to discuss and validate the findings on the three perspectives of market, process and technology.

Based on the focus groups and the analysis of the Braasch group, artefacts on market and process level have been developed. As the main outcome, the requirements for a suitable software architecture have been identified and the existing SusCRM architecture has been adapted for the use in the automotive retailer environment.

\section{RESEARCH FINDINGS}

\section{MARKET NEEDS AND FEASIBILITY ANALYSIS}

A key objective of $\mathrm{ReCaB}$ was the investigation of the dealership specific car sharing process with respect to a customer-oriented feasibility. The study focused in particular on the question of how the customers rate the car sharing process and whether specific needs can be derived - especially outside the major metropolitan areas in smaller towns or rural areas. Existing studies and publications about car sharing have been investigated and information about design and evaluation of car sharing models extracted. These were compared with the dealership specific car sharing process and assessed the 
feasibility, as well as the demand. The unanswered questions after the literature study and analysis, which often were caused by the uniqueness of the car dealership approach or regional circumstances, are discussed and answered within qualitative focus groups. As a matter of priority, the following questions should have been answered and the results are summarized shortly:

1) Who are the target groups of a car sharing offer from the dealership and what benefits do they want to achieve with using car sharing services?

2) Is there a demand on customer side for car sharing offers by car dealerships and to what extent are car dealerships rated as suitable providers of car sharing?

3) What evidence is arising for the design of car sharing processes in general and in particular for the car dealership specific car sharing process?

In the investigation of target groups initially the fundamental distinction between private and business customers was done. Outstanding insights were gained within the identification of target groups in the private customer segment in line with the concept of social milieus and related studies in the field of car sharing (Teiwes-Kügler, 2006; Wilke et al., 2007). Major target groups for car sharing deals were identified in the milieu of "Educated Liberals" and "Educated Petty Bourgeois". The attitude of "Educated Liberals" often is anti-material and ecologically driven and therefore they have retentions regarding offers from car dealerships. These negative attitudes can be encountered with an ecologically based marketing strategy within the SusCRM approach. With a growing offer of car sharing services, additional target groups can be won, e.g. car-friendly customers. According to the results of the focus groups, these customers especially are valuing car dealerships as high quality service providers. A competitive advantage can be identified here compared to "traditional" car sharing companies.

A classification of target groups in milieus of important business customers is not possible. In the B2B segment, no relevant studies are available and no quantitative research exists. However, it could be hypothesized within the framework of conducted focus groups that we can distinguish three target groups:

1) Companies with their own fleet (mostly larger businesses): For these companies, car sharing is an option to cover peak demands. A collection and return service of vehicles is mandatory here. On the other hand, these companies are interested in certain circumstances on a corporate car sharing operated by a car dealership as part of fleet management.

2) Companies with their own fleet and greatest need for mobility in the field of special transports (e.g. certain crafts or assembler companies, as well as strong industrial company): Due to the need for special transport devices and equipping, the vehicles are not substitutable with a car sharing service. Conceivable is the use of car sharing, e.g. by salesmen of the company.

3) Companies without an own fleet (mostly smaller companies or companies with rather low and irregular demand for mobility): For these companies, the use of "public" car sharing is an option for base load coverage, since running an own fleet is economically unattractive.

Another important finding in this regard was that the use of mobility in companies is partly done heterogeneously and without control or acknowledgment of a central unit. A car sharing provider can therefore perceive an important advisory function, through which the provider accommodates the mobility needs, evaluates and elaborates an optimized mobility concept, e.g. within the fleet management for the customer. This may also enable a concrete consideration and integration of the specific operational processes of the company.

For business and private customers, the simple and comfortable character of a car sharing service is highly important. That means an easy access to the system, to the vehicles and the stations. The greatest obstacles of use arise from breaking away from existing mobility routines. Because of this the new service should be seamlessly integrated into existing and often simple mobility routines (using a private car). Particularly, affine to change their mobility routines are the ones who are in a situa- 
tion where they (have to) look for new routines (e.g. birth of a child, moving house). For the car sharing offer by car dealerships this means that it is particularly important to integrate the offer in the existing services and to make the interfaces seamless. The requirement of simplicity of the service can also be found in very concrete examples such as the demand for easy-to-use small vehicles. For business customers the tendency for simplicity is even more pronounced as for retail customers, e.g. clear demands for a collection and return service for vehicles can be identified as well as fuel services by the car sharing provider.

The findings led to the belief that there is a strong justification for car sharing and other mobility service offerings from the car dealership. This resulted in particular from the fact that existing structures and processes can be used at the dealership to fulfill such requirements, in order to gain competitive advantages over existing car sharing services and to offer economic synergies over time. These synergies are presented below. While $\mathrm{ReCaB}$ mainly focused on the car sharing service, further (mobility) services extensively are taken into consideration in the following.

\section{PRESENTATION OF SYNERGY POTENTIAL IN SERVICES AND PROCESSES}

A non-exhaustive taxonomy will be introduced. The taxonomy shows services and the related processes of the "traditional" core business and the possible new mobility services. The aim in this presentation is to show by example how they can be combined reasonably, as well as improved properties are possible with high competitiveness and customer satisfaction due to synergy effects. Figure 2 shows a first overview of services from the car dealership divided in core business and new mobility services.

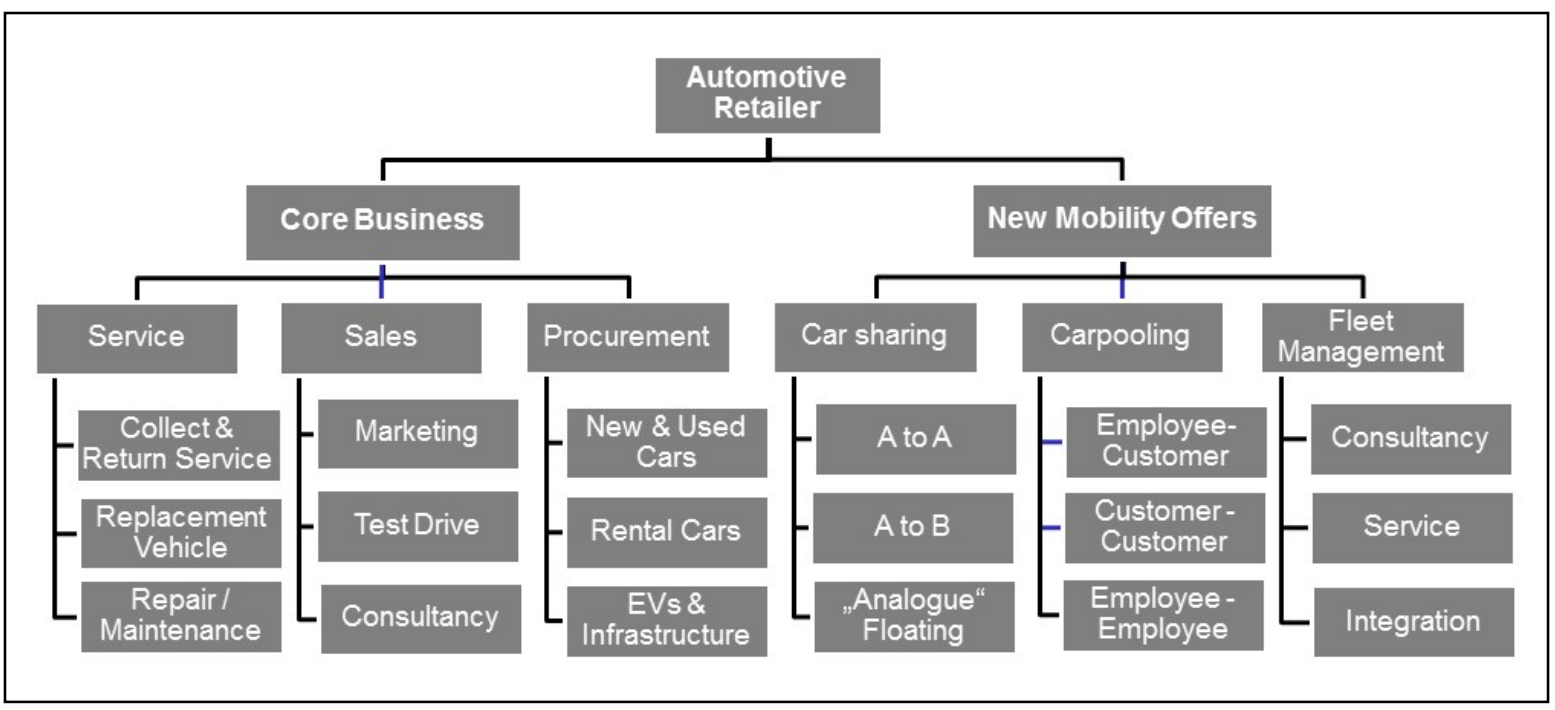

Figure 2. Taxonomy core business/new mobility services

In addition to car sharing, other mobility services like carpooling and fleet management are also listed. Carpooling is the parallel use of a vehicle by several people. By increasing the utilization, carpooling conserves resources and saves emissions. This is transparent by the calculation of $\mathrm{CO}_{2}$ emissions on the basis of passenger-kilometers. There are several meaningful combinations for carpooling possible. Not only customers can share a car, but also employees can carry customers (as an additional service) or other employees. A precondition is the ability of a reasonable synchronization of all journeys on the basis of a complete journey pool (customer journeys, traffic, journeys home staff, etc.). A huge synergy potential both in terms of cost but also in terms of sustainability is possible.

Furthermore, a combination of "employee-employee carpooling" with the already established collection and return service within the garage service enables a new form of car sharing, which was 
named "analogue-floating-car sharing". In this special service, the customer does not have to pick up the vehicle at a station, but the car is delivered to places of his choice (e.g. at home) by a dealership employee and picked up again. Such a trip can be combined with the trip home of the employee and he could get a lift to the workplace the next day by another employee again. Within ReCaB the residence of all 180 employees of the dealership group Braasch was analyzed and it was found a high degree of coverage for the regional catchment area of the group. With the analogue-floating-car sharing a very customer-friendly service can be created with high comfort and possibly greatly reduced cost resulting in an attractive price. However, the necessary matching of routes is very complex and can only be solved with the help of ICT.

The new mobility services also provide opportunities to promote the core business. These opportunities lie, for example, in sales by integrating test drives for EVs in the car sharing offer. Figure 3 shows a generic car sharing process to illustrate the synergy effects at the process level by example.

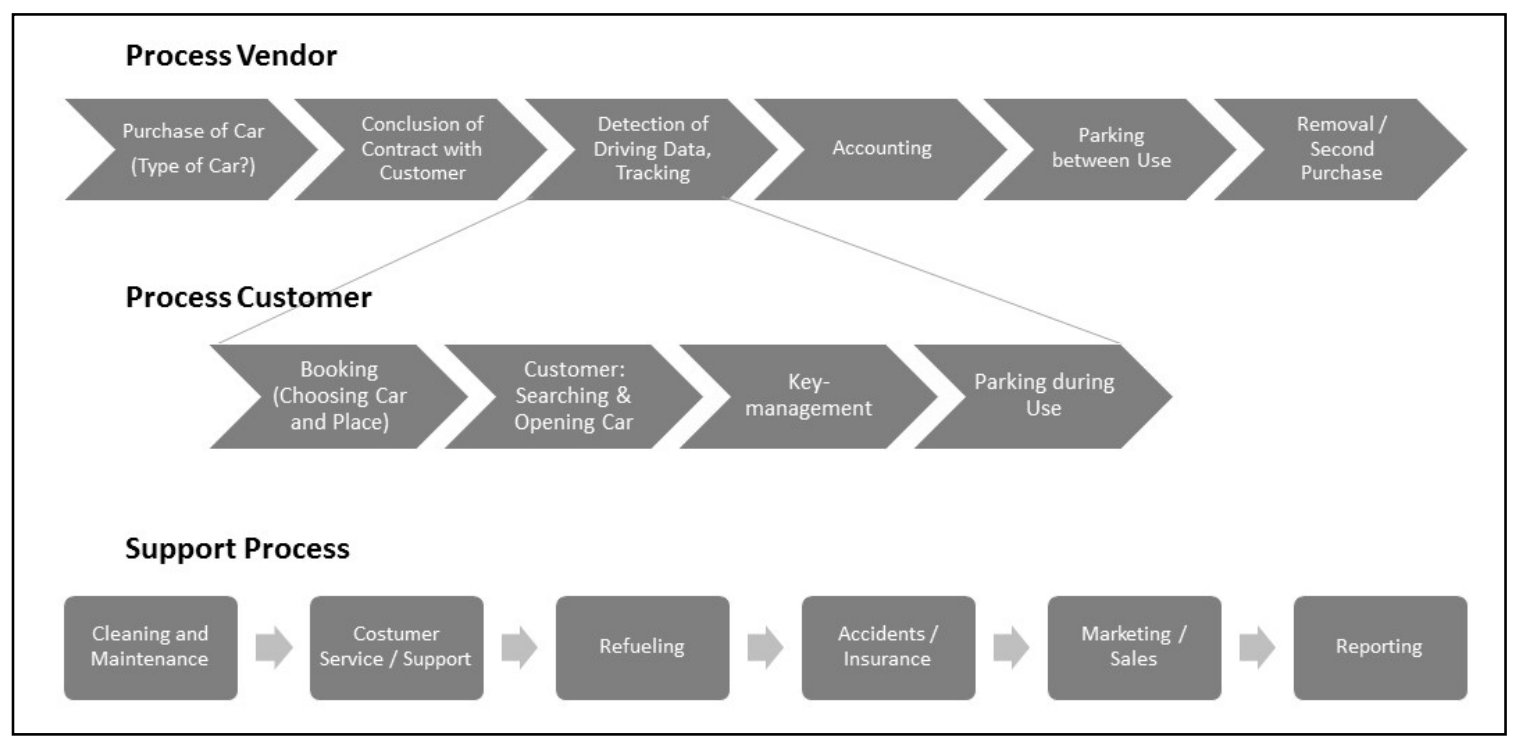

Figure 3. Process map of a generic car sharing offer

It is clear that both with the providing and the supporting processes of car sharing, many processes exist that overlap with those of the core business. This applies, for example, to the procurement process, the invoicing, as well as for cleaning and maintenance.

However, in order to exploit the available synergies, the synchronization and coordination of important processes is required. This only is possible by an integration and adaptation of existing ICT solutions and the development of new applications for both the customer and the provider.

\section{SOFTWARE ARCHITECTURE}

Below, the intended ICT architecture for the realization of the outlined transformation of the car dealership to a regional provider of sustainable mobility is presented. The architecture was designed based on the requirements described and in accordance with the existing design of the software architecture for the SusCRM (Wagner vom Berg, 2013, 2015). Figure 4 shows an overview of the architecture. 


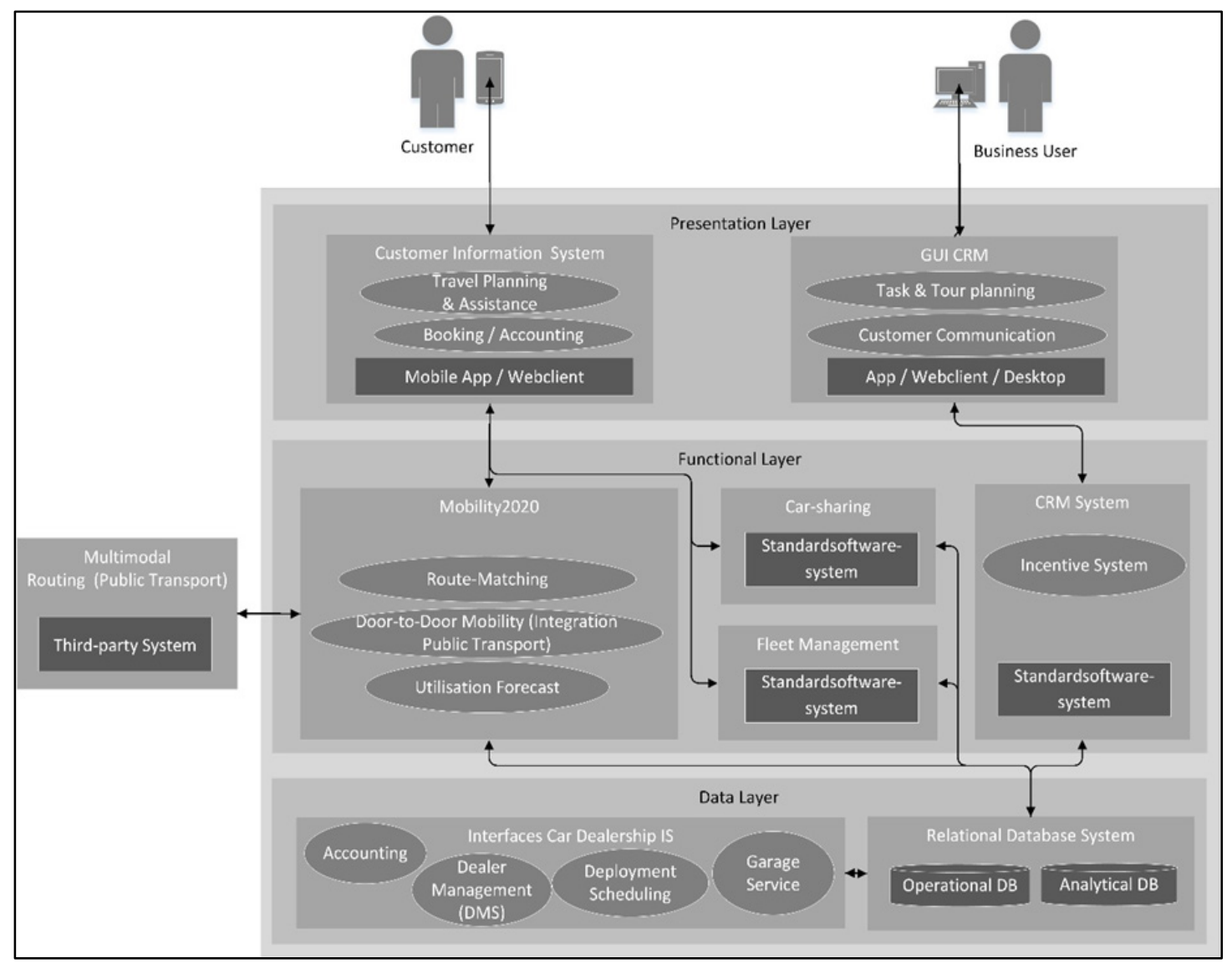

Figure 4. Software architecture

For the architectural design a classic 3-tier architecture with a data, a functional and a presentation layer was chosen. The data layer includes an operational and an analytic database. The analytical database provides analyses, for example, for the utilization forecasts of car sharing vehicles that allow an optimization of vehicle reservations for EVs. Further analyses are conducted within the CRM, for example, customer segmentations and the identification of suitable offers based on existing data. The operational database is primarily used as a data layer for the application system called "Mobility 2020". For this purpose, the existing database of the CRM system can be used. This carries specific advantages that were proven both conceptually and in practical implementation in the context of the SusCRM evaluation (Wagner vom Berg, 2015). In the data layer, the interfaces to the existing systems in the car dealership are of great importance to enable the out-lined synergies.

The main application in the functional layer is the application system "Mobility 2020". This implements the specific functions to allow the combined offer of mobility services. There are already many established standard solutions for car sharing and fleet management in the market. These are usually delivered as an appliance, a combination of hardware (in the vehicle) and software. The solutions must be integrated into the system at the data level. For facilitating a multimodal travel planning appropriate information systems, route calculations for public transport are needed. In contrast to the applications for the car sharing and fleet management, an interface to an external system is necessary. The CRM system provides, in addition to the adapted standard functionality for marketing, sales and service, innovative functionality that allows usage incentives based on sustainability information, as they have already been implemented in SusCRM. The proposed incentive scheme (Wagner vom Berg, 2015) must be adapted to the specific car sharing use case. Instrumental motivations can be fulfilled with the setting of information-based incentives, for example, by information about the direct comparison of the total cost of ownership of the own vehicle (for the specific vehicle model 
of the customer) with a car sharing use on basis of the individual mobility profile. An easy way to set reward-based incentives would be possible with a bonus program for car sharing use.

In the presentation layer, interfaces for customer communication and on supplier side for business users are needed. These must also be mobile accessible because the employees need to know on the move which routes they have to travel with which vehicle. Because of the mentioned reasons, the tour planning includes explicit distances between workplace and place of residence. These functions can be implemented via the CRM application, for example, within the standard component of a service calendar. However, such adjustments must be made as part of customizing. Of particular importance is the customer application in the presentation layer. With complete integration of the existing opportunities for mobility (own and external services), it can serve the customer as an essential instrument for its entire travel planning and execution. This would be desirable in a long-term perspective, since thus a maximum of customer loyalty can be achieved. The customer also gets within the SusCRM approach information about the average $\mathrm{CO}_{2}$ emissions for a selected mobility option and can compare it with the option of using a private car. However, the integration effort on both the presentation as well as the underlying layers is high and a strong dependency of third party systems is given. In many cases, already realized functions of SusCRM can be used.

The software architecture shown is initially to be interpreted as an ideal solution and its implementation is fraught with challenges. The aim should be to create a package of standard software solutions with correspondingly flexible interfaces, since the high costs usually associated with individual software solutions are not covered by the tight budgets of car dealerships.

\section{Discussion}

As a main outcome of this article, a conception for new mobility services by car dealerships is presented. The literature review showed that a (digital) transformation on the manufacturer level is already in an advanced state. This is true for research in this domain but also for real world services like car2go. The demand for services like car2go is continuously growing, especially in the larger cities. However, flexible, innovative concepts such as the floating car sharing are only feasible in urban or confined areas. This is resulting from the fact that the vehicles are not based at fixed locations, but are parked anywhere by the customer within a metropolitan area and collected there from the next customer. However, this customer-friendly approach is only feasible at a high population/density of customers. Otherwise high costs for the disposition of the vehicles are produced or the workload significantly decreases. In the case of new offerings, such as analogue floating car sharing, car dealerships have the great advantage of being able to draw on existing resources in the form of vehicles and staff. In addition, appropriate infrastructure exists in the form of area-wide sales and service centers. It is also possible to set a decisive impetus to enforce sustainable technologies such as electric vehicles (EVs). New mobility services can serve as a "selling tool" in order to reduce still existing concerns of customers about EVs.

The research on the retailer level, especially in combination with a digital transformation by the use of ICT systems is still fragmentary. The presented approach here comes up with a kind of holistic ICT infrastructure that includes existing systems and services but also enables offering new mobility services and the combination of these services. Simultaneously the SusCRM approach provides tools to bring the new offers successfully to market. This gives the chance both to enable new business offers of retailers and to establish a more sustainable transportation infrastructure on a regional level. Research in this area that both addresses sustainability goals on a general level and supports economical goals on the company level of automotive retailers is new. In these terms, it can be considered as a concrete case study for the application of the SusCRM conception for the branch of car dealerships. 


\section{CONCLUSION}

The presented study has outlined the possibilities for the transformation of car dealerships to providers of sustainable mobility. The contributions are the identification of new services like car sharing and fleet management as well as the design of related processes. Basically, these findings result from an empirical study within an inductive approach in the research project ReCaB. The basic feasibility of the establishment and customer acceptance has been demonstrated, at least in the area of car sharing within $\mathrm{ReCaB}$. The execution in the car sharing field has already started in the real world and there are already a number of car dealerships bringing their own offers to market.

However, this is only a first step towards establishing a comprehensive regional provider of sustainable mobility services in accordance with the SusCRM conception. The software architecture of the SusCRM has been adapted for the specific use in car dealerships. This adaption was done based on the knowledge of the specific infrastructure in car dealerships and the needed ICT infrastructure for the establishment of the new services. Still there is no prototype developed for this specific use case and evaluated in the car dealership environment. An implementation only, based on own efforts, is difficult for car dealerships because of the dealership's lack of know-how as well as tight IT budgets. A further reason is the strong dependency of proprietary information systems provided by automotive manufactures; for example, systems for maintenance service management or car rental programs. These manufactures software systems often have a lack of external interfaces or accompany with huge integration efforts. So the dealerships are reliant on appropriate (standard) solutions developed and made available on the market. However, this approach appears particularly in rural areas successful where public transport services are heavily declining. For full implementation, the presented ICT support is imperative.

Based on the already mentioned preliminary works the presented concepts will be conducted within the project "NEMo - Sustainable fulfilment of mobility needs in rural regions". NEMo is a research project funded with $€ 1.54$ million by the Volkswagen foundation. NEMo is an interdisciplinary and transdisciplinary project with the participation of eight professorships from computer science, economics, social science and law from universities in Oldenburg, Brunswick and Lüneburg. Furthermore, many partners at a municipality level and from industry are involved. NEMo aims to develop an ICT platform to support integrated mobility concepts including private and public transport. Car dealerships are considered as one of the very important players within this concept.

\section{ACKNOWLEDGEMENT}

This work is part of the project "NEMo - Sustainable satisfaction of mobility demands in rural regions". The project is funded by the Ministry for Science and Culture of Lower Saxony and the Volkswagen Foundation (VolkswagenStiftung) through the "Niedersächsisches Vorab" grant program (grant number VWZN3122).

\section{REFERENCES}

Albuquerque, P., \& Bronnenberg, B. J. (2011). Measuring the impact of negative demand shocks on car dealer networks. Marketing Science, 31(1), 4-23.

Athanasopoulou, A., Bowman, H., Nikayin, F., \& de Reuver, M. (2016). The disruptive impact of digitalization on the automotive ecosystem: A research agenda on business models, platforms and consumer issues. Proceedings of 2016 BLED Conference, Bled, Slovenia, June, 19-22, Paper 4.

Bellini, E., Dell'Era C., Frattini F., \& Verganti R. (2016). Design-driven innovation in retailing: An empirical examination of new services in car dealership. Creativity and Innovation Management, 25(3).

Belz, F., \& Peattie, K. (2009). Sustainability marketing: A global perspective. West Sussex: Wiley \& Sons.

Bellos, I., Ferguson, M., \& Toktay, L. B. (2016). The car sharing economy: Interaction of business model choice and product line design. Georgia Tech Scheller College of Business Research Paper Series, No. 2016-054. 
Berman, S. J., \& Bell, R. (2011). Digital transformation: Creating new business models where digital meets physical. IBM Global Business Service Executive Report (pp. 1-17). IBM Institute for Business Value.

Black, W. R. (2010). Sustainable transportation: Problems and solutions. New York, London: The Guilford Press.

Canzler, W., \& Knie, A. (1994). Von der Automobilität zur Multimobilität. die Krise des Automobils als Chance für eine neue Verkehrs- und Produktpolitik [From automotive mobility to multimodal mobility. The crisis of the automobile as a chance for a new transportation and product policy]. In W. Fricke and E. Fricke (Eds.), Zukunftstechnologien und gesellschaftliche Verantwortung. Dietz Jabrbuch Arbeit und Technik (pp. 171-181). Dietz: Bonn.

Canzler, W., \& Knie, A. (2009). Grüne Wege aus der Automobilkrise. Vom Autobauer zum Mobilitätsdienstleister [Green ways out of the automotive crisis. From car manufacturer to mobility vendor]. Berlin: Heinrich-BöllStiftung.

Ceschin, F. (2010). How to facilitate the implementation and diffusion of sustainable product-service systems? In F. Ceschin, C. Vezzoli, \& J. Zhang (Eds.), Sustainability in design: now! Challenges and opportunities for design research, education and practice in the XXI century (pp. 440-454). Sheffield: Greenleaf Publishing.

Ciari, F., Balac, M., \& Balmer, M. (2015). Modelling the effect of different pricing schemes on free-floating carsharing travel demand: A test case for Zurich, Switzerland. Transportation, 42(3), 413-433.

Deutscher Bundestag. (1998). Konzept Nachbaltigkeit - Vom Leitbild zur Umsetzung: Abschlussbericht der EnquêteKommission "Schutz des Menschen und der Umwelt" [Conception of sustainability - From general principals to action: Final report of the Enquête-commission „Protection of people and environment" $]$. Bonn: Universitäts-Buchdruckerei.

Desyllas, P., \& Sako, M. (2013). Profiting from business model innovation: Evidence from pay-as-you-drive auto insurance. Research Policy, 42(1), 101-116.

EEA Energy Environment Agency (2011): Transport final energy consumption by mode. Copenhagen: European Environment Agency.

EEA (European Environment Agency). (2013). Final energy consumption by mode of transport. Copenhagen: European Environment Agency.

Eurostat (2015). Energy, transport and environment indicators. Luxembourg: Publications Office of the European Union.

Firnkorn, J., \& Müller, M. (2015). Free-floating electric carsharing-fleets in smart cities: The dawning of a postprivate car era in urban environments? Environmental Science \& Policy, 45(1), 30-40.

Fitzgerald, M., Kruschwitz, N., Bonnet, D., \& Welch, M. (2014). Embracing digital technology. MIT Sloan Management Review, 55(2), 1-12.

Hanelt, A., Piccinini, E., Gregory, R. W., Hildebrandt, B., \& Kolbe, L. M. (2015). Digital transformation of primarily physical industries: Exploring the impact of digital trends on business models of automobile manufacturers. 12th International Conference on Wirtschaftsinformatik, Osnabrück, Germany.

Hevner, A., \& Cahtterjee, S. (2010). Design research in information systems. New York: Springer.

Hevner, A., March, S. T., Park, J. \& Ram, S. (2004). Design science in information systems research. MIS Quarterly, 28(1), 75-105.

Hilty, L. M. (2010). Information and communication technologies for a more sustainable world. In D. Haftor \& A. Mirijamdotter (Eds.). Information and communication technologies, society and buman beings: Theory and framework (pp. 410-418). Hershey, PA: IGI Global.

Hilty, L. M., Lohmann, W., \& Huang, E. M. (2011). Sustainability and ICT: An overview of the field. Notizie di POLITEIA, 27(104), 13-28.

Hinterberger, F., Burger, E., Jasch, C., Kaltenegger, I., \& Hammerl, B. (2008). PDL Strategien: Erarbeitung von bedarfsfeld- und branchenspezifischen Strategien zur Entwicklung und Umsetzung von ProduktDienstleistungsinnovationen [PDL strategies: Elaboration of demand-area and industry-sector-specific strategies for development and execution of product-service-innovations]. Berichte aus Energie-und Umwelfforschung. Wien: BMVIT. 
ICT-Platform to transform Car Dealerships to Regional Providers of Sustainable Mobility Services

International Transport Forum. (2010). Transport outlook. 2010: The potential for innovation. Retrieved from http://www.internationaltransportforum.org/Pub/pdf/10Outlook.pdf

Knie, A. (2005). Auto im Kopf. Die Auswirkungen moderner Verkehrsinfrastruktur auf die Mobilität der Bevölkerung im ländlichen Raum [Car in mind. Impact of modern traffic infrastructure on mobility of people in rural areas]. Zeitschrift für Agrargeschichte und Agrarsoziologie 53(1), 59-69.

Krueger, R. A., \& Casey, M. A. (2000). Focus groups: A practical guide for applied research (3rd ed.). Thousand Oaks, CA: Sage Publications.

Lenz, B., \& Fraedrich, E. (2016). New mobility concepts and autonomous driving: The potential for change. In M. Maurer, J. C. Gerdes, B. Lenz, \& H. Winner (Eds.), Autonomous driving (pp. 173-191). Berlin: Springer.

Mehl, R., \& Kuhnert, F. (2013). Automotive retail - Die Zukunft beginnt jetzt [Automotive retail - future starts now]. NTTT Data Deutschland GmbH.

Merriam, S. B. (2009). Qualitative research: A guide to design and implementation. San Francisco, CA: Jossey-Bass.

Mont, O. (2002). Clarifying the concept of product-service system, Journal of Cleaner Production, 10(3), 237-245.

Neckel, P., \& Knobloch, B. (2005). Customer relationship analytics: Praktische Anwendung des Data-Mining im CRM [Customer relationship analytics: Practical application of Data-Mining in CRM]. Heidelberg: dpunkt-Verlag $\mathrm{GmbH}$

Österle, H., \& Blessing, D. (2000). Business engineering model. In H. Österle \& R. Winter (Eds.), Business engineering. Heidelberg: Springer.

Rautenstrauch, C. (1999). Betriebliche Umweltinformationssysteme [Environmental management information systems]. Grundlagen, Konzepte und Systeme. Berlin, Heidelberg: Springer.

Rautenstrauch, C. (2001). Informatik für Wirtschaftswissenschaftler und Wirtschaftsinformatiker [Informatics for business scientists and information management scientists]. Berlin: Springer.

Richards, L., \& Morse, J. M. (2013). Readme first for a user's guide to qualitative methods (3rd ed.). Thousand Oaks, CA: Sage.

Rishi, S., Stanley, B., \& Gyimesi, K. (2012). Automotive 2020: Clarity beyond the chaos. IBM Institute for Business Value. Retrieved from http://www07.ibm.com/shared_downloads/6/IBM_Automotive_2020_Study_Clarity_beyond_the_Chaos.pdf

Schmöller, S., Weikl, S., Müller J., \& Bogenberger, K. (2015). Empirical analysis of free-floating carsharing usage: The Munich and Berlin case. Transportation Research Part C: Emerging Technologies, 56(7), 34-51.

Setia, P., Venkatesh, V., \& Joglekar, S. (2013). Leveraging digital technologies: How information quality leads to localized capabilities and customer service performance. MISQ, 37(2), 565-590.

Shaheen, S. A., Camel, M. L., \& Lee, K. (2012). Exploring the future of integrated transportation systems in the United States from 2030 to 2050. Application of a scenario planning tool. Retrieved from http:/ /76.12.4.249/artman2/uploads/1/Exploring_the_Future_of_Intelligent_Transportation_Systems_i n_the_United_States_from_2030_to_2050_Application_of_a_Scenario_Planning_Tool_1.pdf

Speshock, C. H. (2010). Empowering green initiatives with IT. A strategy and implementation guide. Hoboken, NJ: Wiley \& Sons.

Steg, L., \& Vlek, C. (2009). Encouraging pro-environmental behaviour: An integrative review and research agenda. Journal of Environmental Psychology, 29(3), 309-317.

Stutzbach, M., Raabe, T., Pfriem, R., \& Becker, U. J. (2001). Machbarkeitsstudie zum Thema Car-sharing in der Fläche [CIF) (Feasibility study for car-sharing in rural areas]. BMBF.

Subramony, D. P., Lindsay, N., Middlebrook, R. H., \& Fosse, C. (2002). Using focus group interviews. Performance improvement, 41(8), 40-47.

Teddie, C., \& Tashakkori, A. (2008). Foundations of mixed methods research: Integrating quantitative and qualitative approaches in the social and behavioral sciences. Thousand Oaks, CA: Sage. 
Teiwes-Kügler, C. (2006). Milieubeschreibungen einschließlich Beschreibungen der Mobilitätsmuster zur repräsentativen Stichprobe der Nicht-Kundenbefragung [Milieu descriptions including descriptions of mobility patterns as a representative sample of non-customer-survey]. Sehnde: BMWi.

Terriena, C., Maniak, R., Chenb, B., \& Shaheen, S. (2016). Good practices for advancing urban mobility innovation: A case study of one-way carsharing. Research in Transportation Business \& Management, 20(9), 20-32.

Wagner vom Berg, B. (2013). Sustainable mobility accelerated by a sustainability CRM. In J. Comby, K. A. T. Eames, L. Guiherý, J. Marx Gómez, \& A. U. Öktem (Eds.), Developing sustainability. A collection of selected papers by the Dorich House Group of European Universities (pp. 297-312). Istanbul: Istanbul Bilgi University Press.

Wagner vom Berg, B. (2015). Konzeption eines Sustainability Customer Relationship Managements (SusCRM) für Anbieter nachhaltiger Mobilität [Conception of a Sustainability Customer Relationship Management (SusCRM) for vendors of sustainable mobility services]. In J. Marx Gómez (Ed.). Oldenburger Schriften zur Wirtschaftsinformatik. Aachen: Shaker.

Wielinski, G., Trépanier, M., \& Morency, C. (2015). What about free-floating carsharing? A look at the Montreal, Canada, case. Transportation Research Record: Journal of the Transportation Research Board, 2536, 28-36.

Wilke, G., Böhler, S., Bongardt, D., \& Schäfer-Sparenberg, C. (2007). Zukunft des Car-sharing in Deutschland [Future of car-sharing in Germany]. Wuppertal.

Yoo, Y. J., Henfridsson, O., \& Lyytinen, K. (2010). The new organizing logic of digital innovation: An agenda for information systems research. Information Systems Research, 21(4), 724-735.

\section{BIOGRAPHIES}

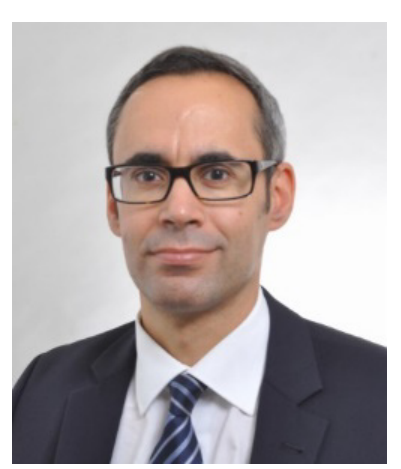

Dr.-Ing. Benjamin Wagner vom Berg is a postdoctoral researcher in the Department of Business Informatics/VLBA of the Carl von Ossietzky University of Oldenburg. Before his university career he worked for eight years as a senior consultant for Customer Relationship Management for a mid-sized German software vendor. His research activities are located in the area of Sustainability CRM and sustainable transportation systems.

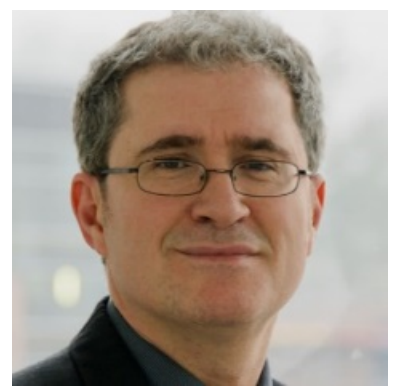

Prof. Dr.-Ing. Jorge Marx Gómez studied Computer Engineering at the Technical University of Berlin. Subsequently, he worked for DeTeWe AG for twelve years as a development engineer for digital transmission and switching technology. He was a research assistant at the Institute for Technical and Operational Information Systems at the Otto von Guericke University in Magdeburg, where he specialized in business informatics at the University of Magdeburg. Since October 2005, he has been Professor of Business Informatics at the Carl von Ossietzky University of Oldenburg.

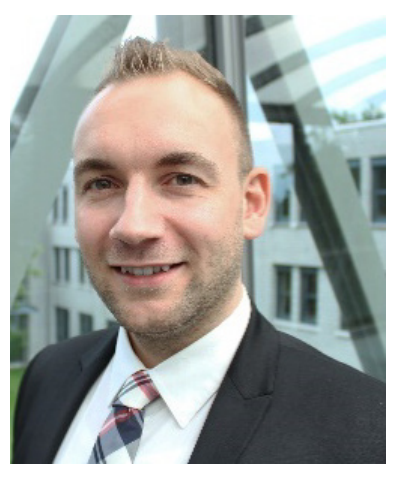

Alexander Sandau (MSc). After studying computer science at the Technische Universität Braunschweig, Alexander Sandau moved as research assistant to the Department of Business Informatics/VLBA of the Carl von Ossietzky University of Oldenburg. Mobility services and autonomous vehicle management platforms are the main focus of his research. 